\title{
The effects of welding speed on the microstructure and mechanical properties of marine-grade aluminium (AA5754) alloy joined using MIG welding
}

\author{
B. Çevik ${ }^{1 *}, \mathrm{M} . \mathrm{Koç}^{2}$ \\ ${ }^{1}$ Department of Welding Technology, Düzce University, 81850 Düzce, Turkey \\ ${ }^{2}$ Department of Ship Construction, Bandırma Onyedi Eylül University, 10200 Balikesir, Turkey
}

Received 28 February 2019, received in revised form 16 May 2019, accepted 28 May 2019

\begin{abstract}
AA5754 aluminium alloys are commonly used in marine and offshore applications as well as in shipbuilding equipment. It is of great importance to weld this alloy in these industrial areas. This study investigated the penetration, microstructure, and mechanical properties of AA5754 Al alloy sheets that were joined using robotic metal inert gas (MIG) welding at different welding speeds. The joints were welded at three welding speeds by keeping the welding current constant, and then macrostructure and microstructure of the samples taken from these joints were examined. Afterward, their hardness, tensile and bending tests were carried out. It was found that the increase in the welding speed decreased the amount of accumulated metal and the penetration rate. Formation of macro- and micro-porosities was observed in the root sections of the weld seams. It appeared that the welding speed increased, the quantity and size of these defects increased, and the mechanical properties were negatively affected by the increase in the welding speed.
\end{abstract}

Key words: marine grade aluminium, AA5754, MIG welding, microstructure, mechanical properties

\section{Introduction}

Weight saving is one of the important factors reducing costs in the offshore and marine sectors. Offshore and marine technology is planned with cost and environmental factors in mind mainly due to the decrease in the natural resources required for life, alongside the increase in the human population [1-3]. Many sectors, such as offshore and marine, aircraft, defense, and automobile industries, have conducted studies aimed at minimizing $\mathrm{CO}_{2}$ emission [3, 4]. These studies have focused particularly on reducing energy consumption. Energy generally is consumed using light metals/materials. Aluminium, for example, is one of such metals used to reduce weight and thus is widely used in offshore and marine structures [2, 4-8].

Aluminium is almost three times lighter than steel. Also, it has numerous outstanding properties such as good mechanical properties, high corrosion resistance, and perfect formability, as well as high thermal and electrical conductivity [8-10]. Its low density and high yield strength, in particular, signify that manufacturers use it in aircraft, vessels, and land vehicles to reduce their weight $[4,6]$. Marine grade (AA5XXX) aluminium alloys are also extensively used in various marine and offshore applications as well as in shipbuilding equipment. 5XXX series aluminium alloys are Al-Mg alloys $[2,8]$. Unlike the polymer matrix composites, marine grade AA5XXX aluminium alloys are commonly used in the manufacturing of vessels since they are lightweight, highly resistant to corrosion, and inflammable (unburned). It is also used in architecture, the production of pressurized vessels and the fuel tanks of the vehicles, and the welded chemical and nuclear structures $[1,4,8]$. The fact that aluminium and its alloys are so widely used suggests the welding requirements [2-9]. However, aluminium and its alloys have poor welding capabilities [10-12]. Therefore, researchers have been trying to develop solutions for welding some of the aluminium alloys over the past

*Corresponding author: e-mail address: bekircevik@duzce.edu.tr 
twenty years [13-16]. The issues of porosity, excessive material loss, and hot cracking among certain aluminium alloys during welding have yet to be solved [13-18]. Certain aluminium alloys can be welded using metal inert gas (MIG) welding. MIG is usually used to weld steels and non-ferrous metals [12]. The heat necessary for welding via MIG is generated by heating the resistance in an electrode via the welding current that passes through the electrode and the arch forming between the melting, the continuously fed wire electrode, and the workpiece. The welding wire is automatically sent to the arc zone, melts, and forms the welded metal [12-19]. In MIG method, the weld zone is protected by an inert gas. Argon ( $\mathrm{Ar}$ ) and helium $(\mathrm{He})$ gases, as well as a mixture of both at different rates, can be used as shielding gas when welding aluminium alloys $[12,14,16,19,20]$.

Certain specific properties must be taken into consideration when welding aluminium and its alloys by traditional methods. One of these properties is their having a higher level of thermal conductivity than various steels. This negatively affects their welding capability and thus makes it difficult for one to melt aluminium. Insufficient melting and pores can occur at the weld seam, given that aluminium melts late and hardens quickly. Likewise, when the annealing colour during the melting does not form, this makes the manual welding of the aluminium alloys difficult [17-20]. The defects caused by the operators and the properties of the materials can be reduced by welding the aluminium alloys via MIG method integrated into the robotic systems in which all of the parameters can be controlled $[12,20]$. The studies on joining the aluminium alloys by MIG welding method have been increasingly continuing. In the study by Dudzik [21], 5083, 5059, and 7020 aluminium alloys were welded by MIG welding method, and their mechanical properties were examined. In the study, it was determined that 7020 aluminium alloy had maximum tensile strength, and its tensile strength was higher at the rates of 7.2 and $7.5 \%$ than that of 5083 and 5059 aluminium alloys, respectively. In another study, Cueca et al. [22] welded 5083-H116 aluminium alloy using GMAW method and then examined its mechanical and microstructure properties. Their results revealed that the micro-void defects formed in the weld seams, and these defects negatively affected their mechanical properties. In their study, Casalino et al. [23] likewise welded AA5754-H111 aluminium alloy by using fibre laser supported by MIG and investigated the effects of laser and arc forces on the mechanical and microstructure properties of the weld seam. They concluded that high laser force improved the geometry and mechanical properties of the weld seam and also the porosities in the weld seam, and the increase in the laser power decreased the amount of porosity. In their study, Liu et al. [24] welded AA5754 alloy by using the double pulsed gas metal arc welding (DP-GMAW) method and investigated the metallic drop transfer, weld pool profile, and the weld seam geometry, as well as the alloy's mechanical properties. They stated that the increase in the wire feed speed increased penetration. They also reported that metal transfer, weld pool profile, and the weld seam geometry in the DP-GMAW considerably differed from those in the P-GMAW. It is seen in the literature that the problems encountered in welding the aluminium alloys by using the welding process have yet to be resolved entirely. This, therefore, means that further studies on welding of the aluminium alloys are needed [16, 18, 20-24].

In this study, we welded AA5754 aluminium alloy using MIG welding method, and then the macrostructure and microstructure examinations of the samples of the joints were performed, and their hardness, tensile, and bending tests were carried out for the welded samples. The results of the present study, upon eval-

Table 1. Chemical and mechanical properties of AA5754 Al alloy and welding wire

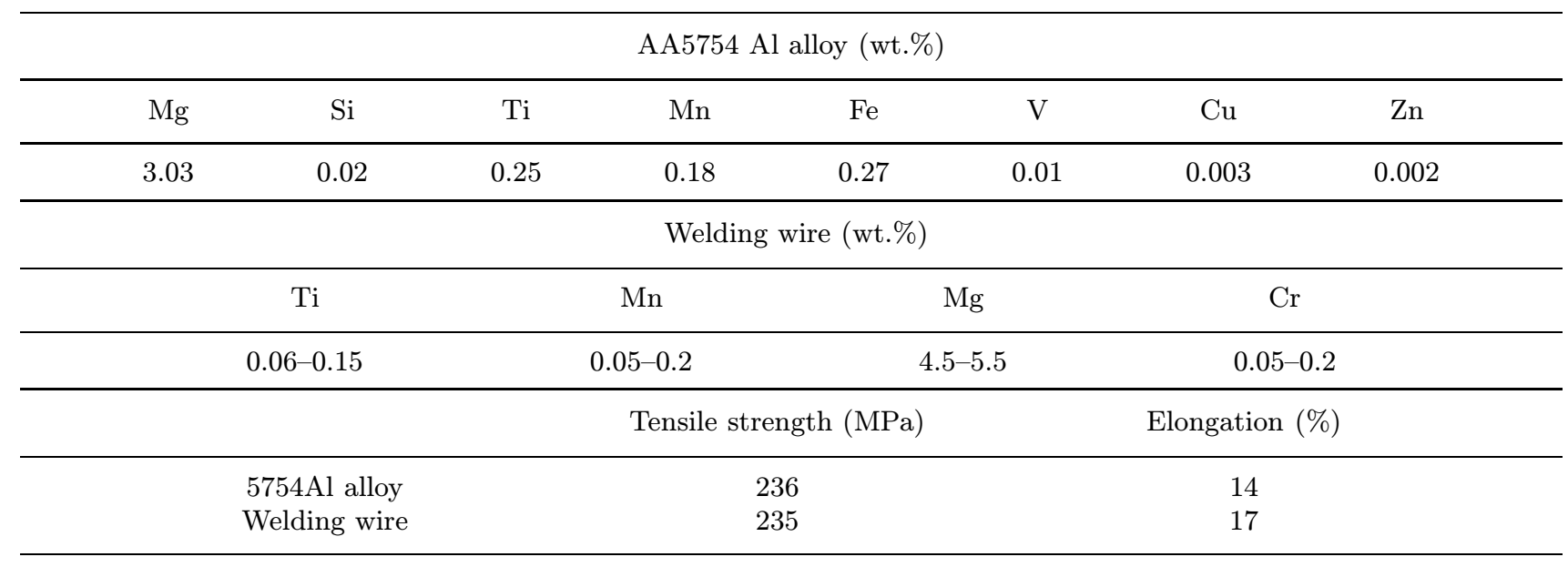


Table 2. Welding parameters

\begin{tabular}{|c|c|c|c|c|}
\hline Welding parameters & Unit & & Value & \\
\hline Welding current & A & & 90 & \\
\hline Voltage & $\mathrm{V}$ & & 18.2 & \\
\hline Welding feed rate & $\mathrm{m} \mathrm{min}^{-1}$ & & 5 & \\
\hline Welding speed & $\mathrm{mm} \mathrm{s}^{-1}$ & & $15,17.5,20$ & \\
\hline Shielding gas & \multicolumn{4}{|c|}{ Argon } \\
\hline Shielding gas flow & $\operatorname{lmin}^{-1}$ & \multirow{2}{*}{\multicolumn{3}{|c|}{$\begin{array}{c}15 \\
1.2\end{array}$}} \\
\hline Welding wire diameter & $\mathrm{mm}$ & & & \\
\hline Welding position & \multicolumn{4}{|c|}{ Horizontal } \\
\hline Sample code & $\mathrm{BM}$ & S15 & S17.5 & $\mathrm{S} 20$ \\
\hline Heat input & $\mathrm{kJ} \mathrm{mm}^{-1}$ & 0.1092 & 0.0936 & 0.0819 \\
\hline
\end{tabular}

uation and interpretation, were evaluated and interpreted in line with the literature.

\section{Experimental}

In this study, AA5754 aluminium alloy samples in the size of $150 \times 50 \times 3 \mathrm{~mm}^{3}$ were joined butt-to-butt using robotic MIG welding method. The samples were fixed butt-to-butt without any cavity before the welding process. The welding processes were carried out using an additional wire (Al5356-AlMg5Cr) having a diameter of $1.2 \mathrm{~mm}$. Table 1 shows the chemical composition and the mechanical properties of the base metal (BM) and the welding wire. A single-sided welding process was carried out in $\operatorname{ESAB}(400 \mathrm{~A}$ ) robotic welding machine by selecting the parameters given in Table 2. The samples were left to cool at room temperature after the welding process.

The macrostructure and microstructure examination as well as hardness, tensile, and bending tests, were carried out on samples joined by the robotic MIG welding. The samples perpendicular to the direction of the welding were sanded using sandpaper no. $600,800,1000$, and 1200 , and then polished with a $3-\mu \mathrm{m}$ diamond paste and a $1-\mu \mathrm{m}$ polishing pad. We etched the samples with Keller's reagent $(150 \mathrm{ml}$ $\mathrm{H}_{2} \mathrm{O}, 3 \mathrm{ml} \mathrm{HNO}_{3}, 6 \mathrm{ml} \mathrm{HF}$ ) for approximately $90 \mathrm{~s}$. The samples' microstructures were carried out using a Metkon inverted-type metal microscope. The microimages were taken from the centre of welding and transition zones. The hardness tests were carried out horizontally on the sections perpendicular to the direction of welding. During the tests, we applied a $200 \mathrm{~g}$ load to the samples for $10 \mathrm{~s}$ by using a Metkon Duroline-M micro-Vickers hardness testing device and then measurements were performed. The hardness measurements were taken from a total of 9 points with $250 \mu \mathrm{m}$ intervals from the weld centre. For the tensile and bending tests, on the other hand, we prepared the samples following ASTM-E8 and EN ISO 5173, respectively. We carried out these two tests using an Alsa tensile device and then performed the fracture surface analysis with FEI Quanta FEG 250 Scanning Electron Microscope (SEM).

\section{Results and discussion}

\subsection{Macrostructure}

Figure 1 shows the images of the samples welded at welding speeds of $15,17.5$, and $20 \mathrm{~mm} \mathrm{~s}^{-1}$ at welding current of $90 \mathrm{~A}$. As a result of the robotic welding processes, smooth weld seams with a proper appearance were obtained. No macro-welding defects such as pores, macro-crack, splash, and burning groove were determined upon the visual inspection of the surfaces of the welded joints. Angular distortion did not occur on the longitudinal or transverse directions of the welded sheets.

Figures $2 \mathrm{a}-\mathrm{c}$ show the penetration, welding width, and welding cap height diagrams of the welded samples. Even though all of the weld seams were properly formed, they had different geometrical properties according to the welding feed rate. The increase in the welding speed led to the decreased penetration and weld seam width, and the increased welding cap height. The increase in the welding speed affects the heat input, the amount of accumulated metal, and the cooling rate [18-20]. Therefore, the amount of metal accumulated in the weld zone decreased with increased welding speed. The decreased amount of metal accumulated in the weld zone caused the width of the weld seam to decrease. Moreover, the increased welding speed resulted in faster solidification, and prevented the accumulated metal from accumulating in a wider zone, thus causing a high cap to form. Fig- 

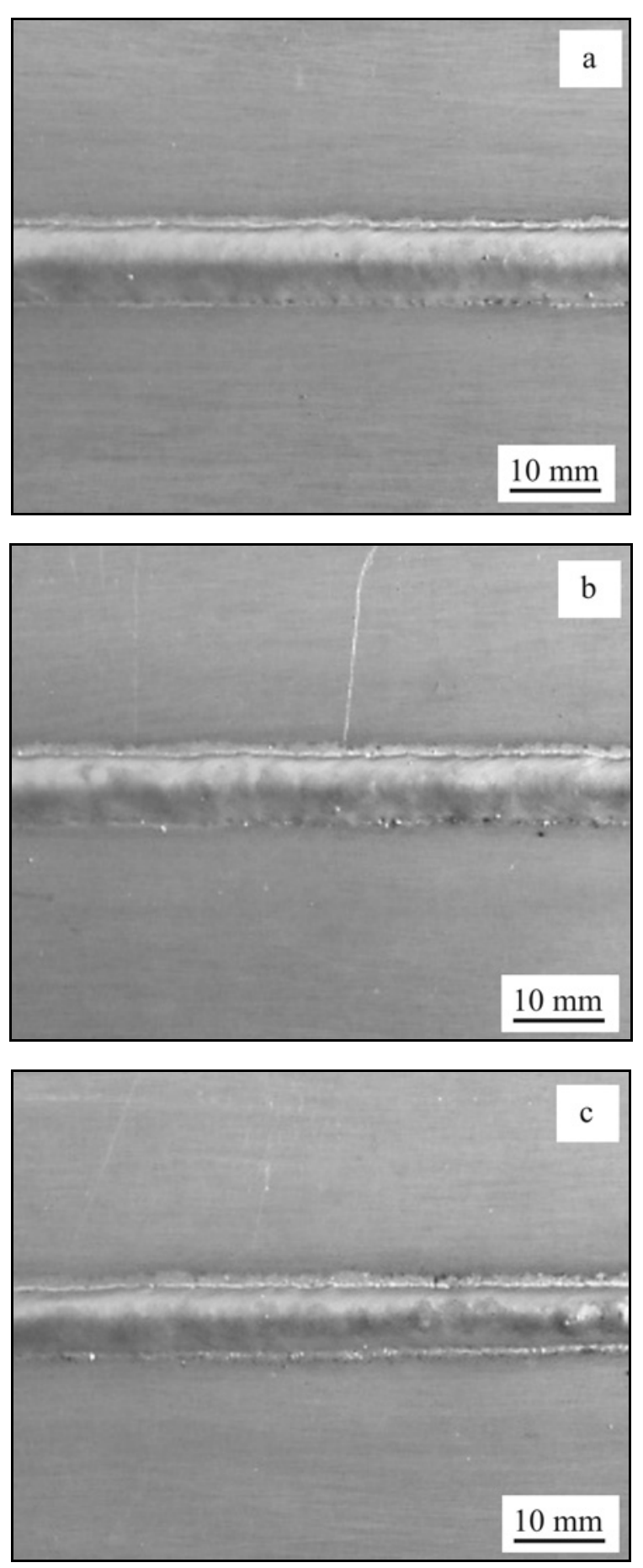

Fig. 1. Surface views of the welded samples: (a) S15, (b) S17.5, and (c) S20.

ure 2 shows the changes that took place in the weld seam as long as the welding speed changed. Full penetration was achieved at the propagation rates of 15 and $17.5 \mathrm{~mm} \mathrm{~s}^{-1}$. However, $100 \%$ penetration was not obtained at the highest welding feed rate. Therefore, the cooling rate based on the heat input affected the penetration of the weld zone. It was also observed that
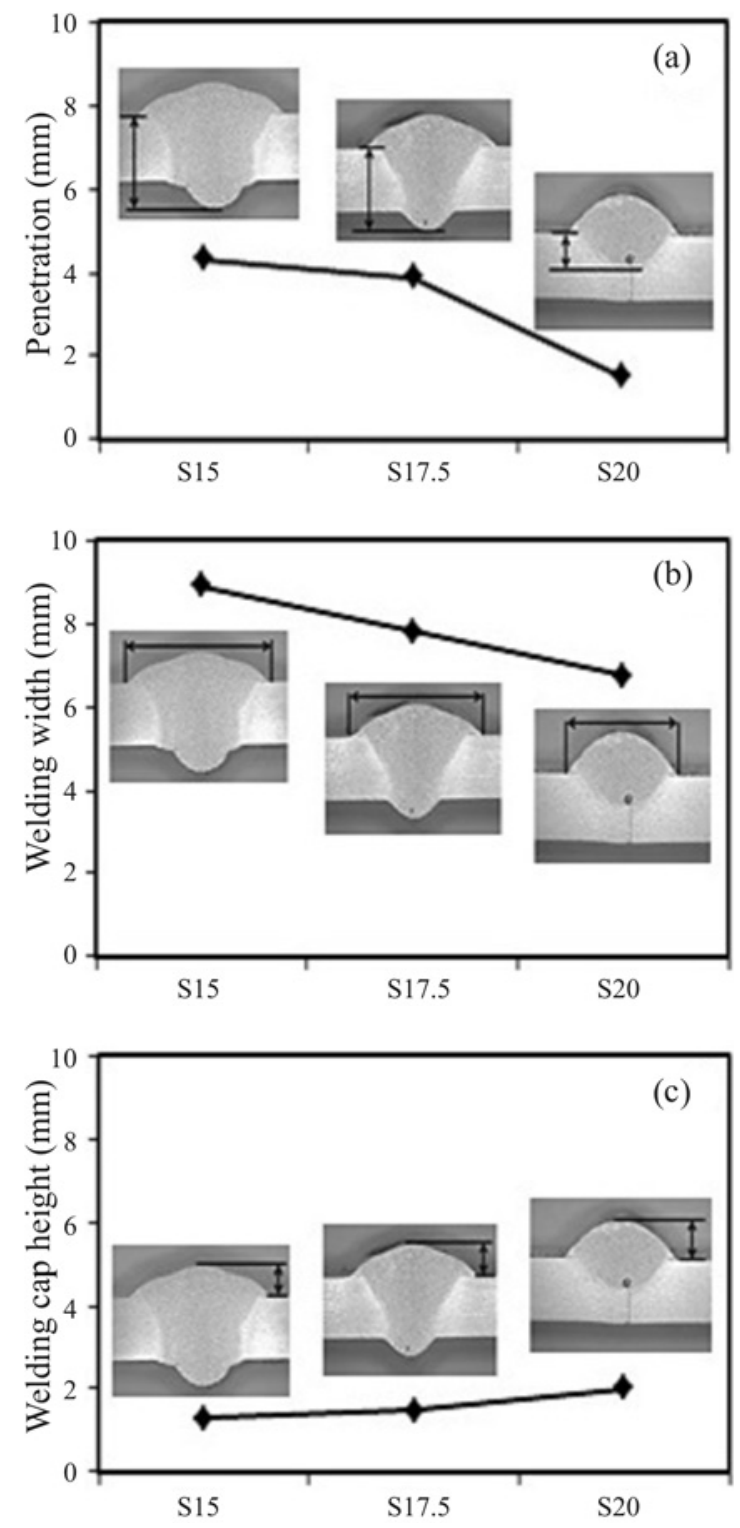

Fig. 2. The properties of the weld seam: (a) penetration, (b) welding width, and (c) welding cap height.

the amount of the filling metal decreased as the additional wire decreased based on the welding speed, which therefore led the penetration to decrease in the root section of the weld seam.

The macro- and micro-porosities were observed in the root sections of the weld seams (Figs. 2, 3). Porosity refers to the spaces or pores caused by the compression of gas within the melted metal and/or non-metal materials during solidification [20]. The solubility of these materials in the liquid metal is higher than in solid metal, which leads to the occurrence of porosity in the weld zone if they are unable to escape from the weld metal during solidification [18]. In the literature, there are two main porosity mechanisms that cause porosity in the welding of aluminium $[18,20-$ 

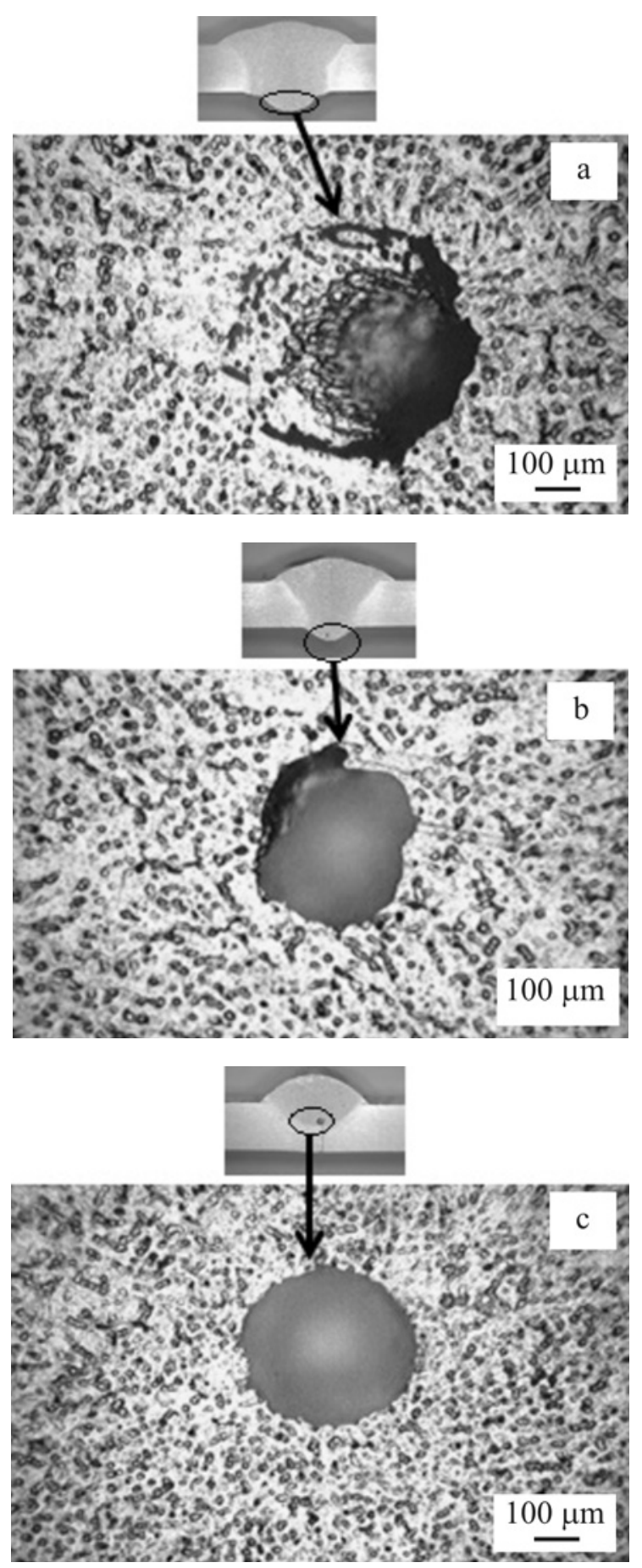

Fig. 3. Micro-porosities in the root region of the weld seam: (a) S15, (b) S17.5, and (c) S20.

24]. The first mechanism is hydrogen dilutions in the weld pool, causing the micro-porosity. When hydrogen in the melted welding metal becomes trapped in the welding pool, it forms micro-porosity due to its quick solidification property [23]. The second mechanism is when the instability of the weld pool causes macroporosity when the gas in the weld metal is trapped
[21-24]. The heat that occurs during the welding process quickly diffuses towards the cold areas due to the high thermal conductivity of the aluminium, in turn causing the weld metal to solidify quickly [12]. Both macro- and micro-porosities occur due to the gas compression during the quick solidification of the weld metal. Additionally, $\mathrm{Mg}$ vaporization that occurs in the weld metal due to the high heat input during the welding process can lead to the micro-porosity $[13,18$ 20, 25]. Caselino et al. [23] reported that insufficient penetration could occur in the weld metal due to the fact that $\mathrm{Al}$ alloys melt late and solidify quickly during the welding process, as well as micro-void and microporosity defects are likely to occur depending on the presence of hydrogen or $\mathrm{Mg}$ loss during the welding process.

\subsection{Microstructure}

Figure 4 shows the microstructures of the weld seams. The images of microstructure were taken from the weld centre and transition zones. When examining their microstructures, it was found that they were composed of fine grains that were homogeneously distributed. The microstructures of the weld centre varied depending on the welding feed rate. It was determined that finer grained microstructures formed in the welding structure as the welding speed increased, which was caused by low heat input that occurred as the welding speed increased. Low heat input did not allow the coarsening of the micro-grains. Large grains formed in the heat affected zone. Çinar et al. [14] declared that the heat input of the aluminium alloys during the MIG caused the coarsening of the grains in the heat affected zone (HAZ) and the weld metal. Moreover, the transition zones of the weld seams displayed similar properties, too. We also observed the formation of grains in the weld metal from the transition zone to the weld centre. However, the analysis of the microstructure did not reveal the presence of either micro-crack or hot-crack defects even though both macro- and micro-porosity defects occurred.

\subsection{Hardness}

Figure 5 shows the hardness distribution of the weld zones. The increased welding feed rate affected the hardness distribution of the weld zone. The hardness values of the weld centre were $63 \mathrm{HV}$ at a welding feed rate of $15 \mathrm{~mm} \mathrm{~s}^{-1}, 67 \mathrm{HV}$ at $17.5 \mathrm{~mm} \mathrm{~s}^{-1}$, and $69 \mathrm{HV}$ at $20 \mathrm{~mm} \mathrm{~s}^{-1}$. In the measurements taken (HAZ) $4 \mathrm{~mm}$ away from the weld centre, the values were $60 \mathrm{HV}$ at $15 \mathrm{~mm} \mathrm{~s}^{-1}, 63 \mathrm{HV}$ at $17.5 \mathrm{~mm} \mathrm{~s}^{-1}$, and $59 \mathrm{HV}$ at $20 \mathrm{~mm} \mathrm{~s}^{-1}$. According to these results, it was observed that the hardness values of the weld zone decreased as the welding feed rate decreased. This can be explained by the fact that the decrease in the weld- 

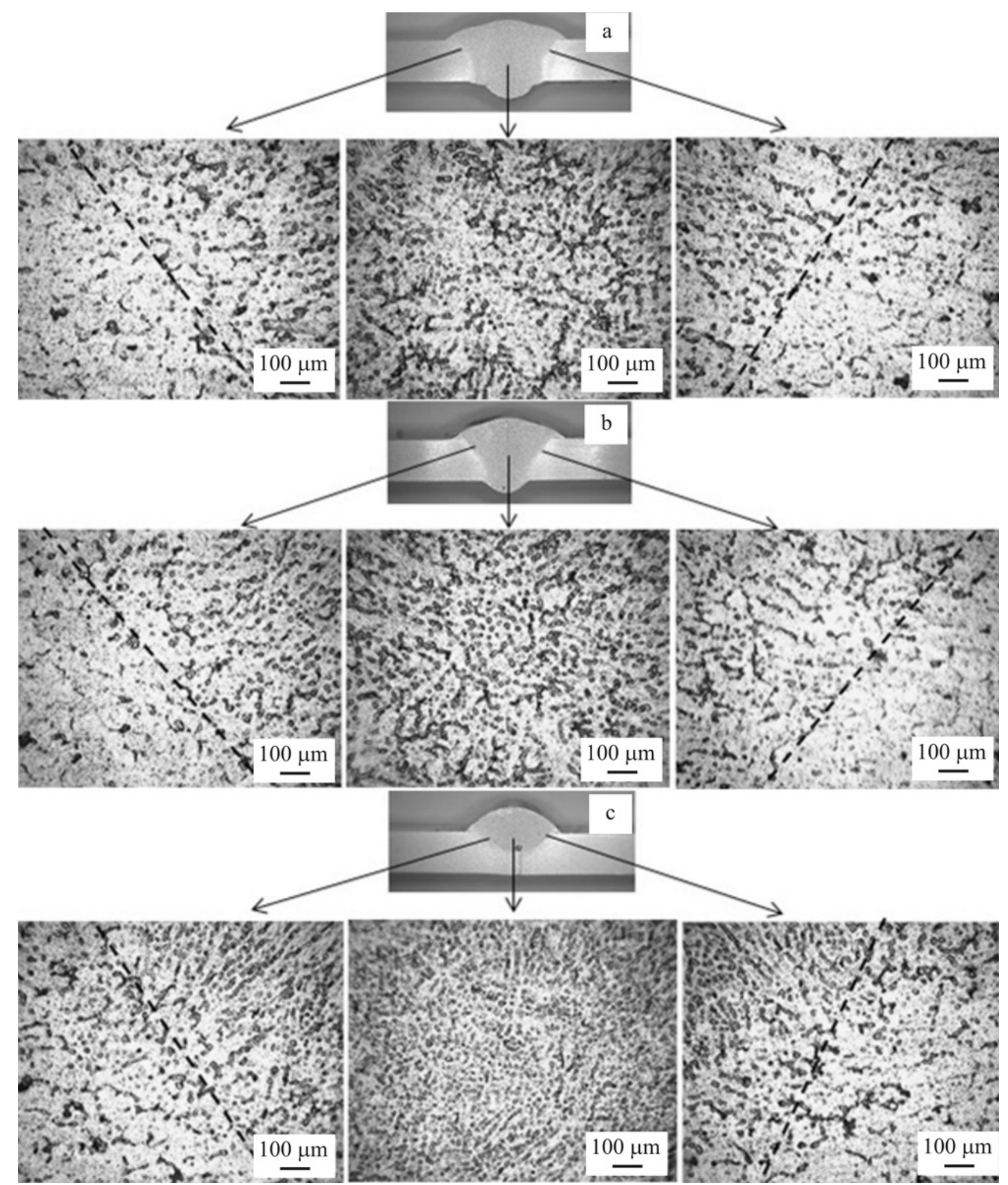

Fig. 4. Microstructures of the welded samples: (a) S15, (b) S17.5, and (c) S20.

ing speed caused higher heat input in the weld zone. The high heat input caused slow cooling, thus leading to a decrease in hardness for both the weld metal and HAZ. It was also thought that the welding wire used in the welding process likely affected the hardness dis- tribution of the weld zone. This significant increase in the hardness of HAZ and the weld metal, compared to the base metal, revealed that the additional welding wire affected the hardness distribution. The possible loss in magnesium content due to the grain coarsening 
Ta ble 3. Tensile test results

\begin{tabular}{|c|c|c|c|c|}
\hline Sample code & $\begin{array}{c}\text { Tensile strength } \\
(\mathrm{MPa})\end{array}$ & $\begin{array}{c}\text { Elongation } \\
(\%)\end{array}$ & $\begin{array}{c}\text { Welding efficiency } \\
(\%)\end{array}$ & Fracture \\
\hline $\mathrm{BM}$ & 236 & 14.2 & - & \\
\hline $\mathrm{S} 15$ & 231 & 10.1 & 97 & \\
\hline S17.5 & 195 & 9.6 & 82 & \\
\hline $\mathrm{S} 20$ & 98 & 11.3 & 41 & \\
\hline
\end{tabular}

in HAZs and especially the fusion at the zones close to the base metal in particular also affected the hardness distribution $[16,18,20]$. It could be asserted that hardness values of the sheets obtained by the deformation during the rolling of these sheets are likely to increase due to the heat input especially in HAZs [18, 21-24]. Thus, many factors were considered to affect the hardness of the weld zone.

\subsection{Tensile strength}

The tensile test was performed to identify the mechanical properties of the base material and the samples welded at the different welding feed rates. Table 3 shows the results of the test. The results of the tensile test revealed that the average tensile strength and elongation values of AA5754 Al alloy (BM), which were used as the base metal in this study, were $236 \mathrm{MPa}$ and $14.2 \%$, respectively. The tensile strength and elongation values of the sample S15, which was welded at the lowest welding feed rate, were $231 \mathrm{MPa}$ and $10.1 \%$, respectively. The tensile strength and elongation values of the sample S17.5, which was welded at the welding feed rate of $17.5 \mathrm{~mm} \mathrm{~s}^{-1}$, were $195 \mathrm{MPa}$ and $9.6 \%$, respectively. The tensile strength

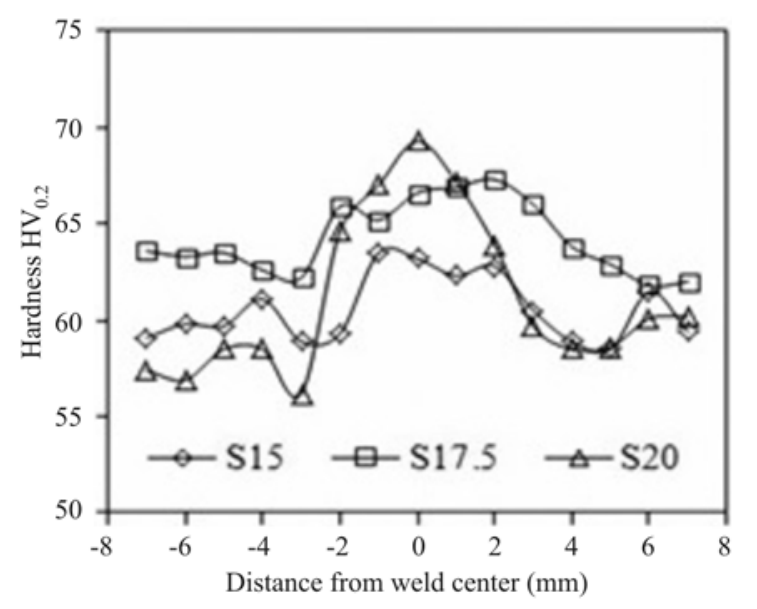

Fig. 5. Hardness distributions of fusion zone in AA5754 aluminium joints.

and elongation values of the sample S20, which was welded at the highest welding feed rate, were $98 \mathrm{MPa}$ and $11.3 \%$, respectively. Based on these results, it was concluded that the tensile strength of the welded samples was lower than that of the base material and the 

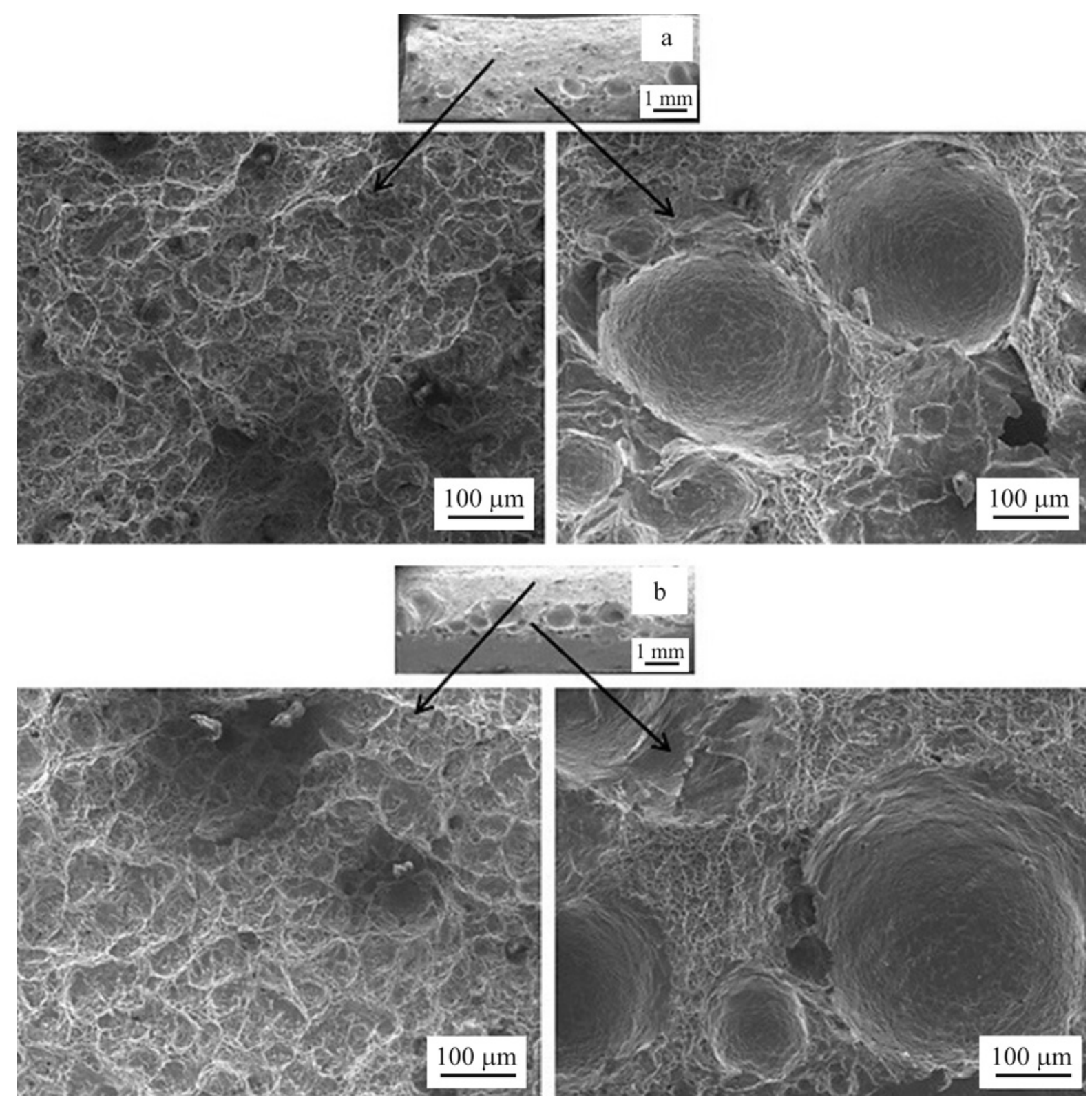

Fig. 6. Fracture behaviour of tensile test samples: (a) S17.5 and (b) S20.

welding efficiency (WE) of the samples S15, S17.5, and S20 decreased by 3,18 , and $59 \%$ in comparison to the base metal.

When the results of the tensile test were examined, it was thought that several factors affected the decrease in the tensile strength. The macro- and microporosities led to a decrease in the tensile strength of the samples S17.5 and S20 in particular. Figure 6 shows SEM images of the fracture surface of the samples S17.5 and S20. When examining the SEM images of the fracture surface of the tensile test samples, it was observed that macro- and micro-porosities formed in the root sections of the weld seams. The macroporosities did not form at the top section of the weld seams, however, the macro-porosities in large sizes up to $1 \mathrm{~mm}$ formed in the root sections of the weld seams. Also, in terms of the fracture surfaces, it was found that the amount and size of the macro-porosities increased with the welding speed. Given that the gases present in the root sections of the weld seam did not abandon the weld metal during the fast solidification of the weld metal, the macro- and micro-porosities formed especially in these zones. Moreover, the microstructural formation and the properties of the weld zone were affected by the effect of the welding speed on the heat input and the cooling rate developing depending on the heat input. AA5754 Al alloys are hardened through cold forming $[8,23,24]$. When this material is reheated above $350{ }^{\circ} \mathrm{C}$, the strength of the material decreases due to its re-crystallization [26]. During the 


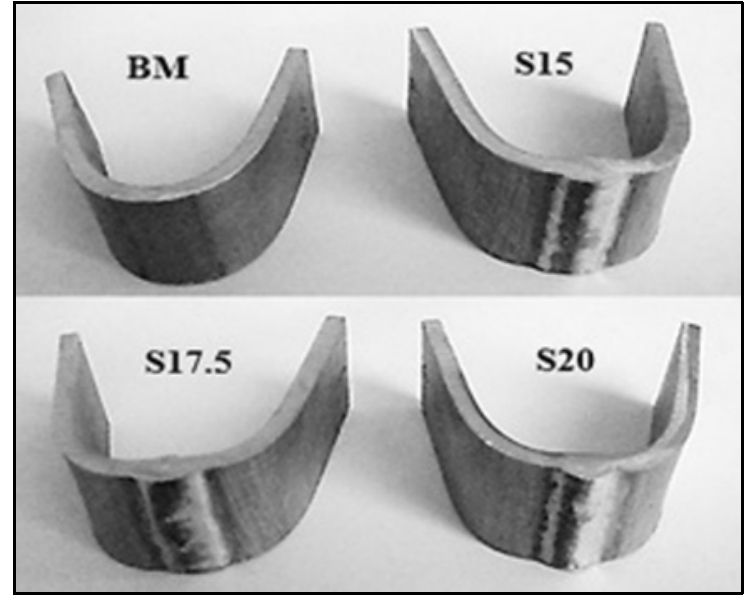

Fig. 7. Samples of the bending test.

MIG welding process, the weld zone was subjected to the temperature above this value, which in turn caused its strength to decrease, especially in the weld zone. The fact that in relation to the welding speed, the rate of filler metal decreased with the decrease in the rate of additional wire and the penetration decreased in the root section of the weld seam in particular negatively affected the tensile strength $[12,18]$.

When examining the fracture surfaces of the welded samples, it was observed that ductile fractures occurred. Aluminium alloys are known to be ductile [20]. Table 3 shows the elongation values of $9-11 \%$ in the welded samples. However, compared to the base metal, the ductility of the welded samples decreased due to the macro- and micro-porosities in the weld seam. Dudzik [21], Cueca et al. [22], Casalino et al. [23], and Liu et al. [24] have all reported that the micro-porosity and porosity defects that occur during the MIG welding negatively affect the mechanical properties of the $\mathrm{Al}$ and its alloys. Unfortunately, there has been yet no solution to this issue.

\subsection{Bending test results}

Figure 7 shows the images of the bending behaviour of the base material and the welded samples. The $180^{\circ}$ cap bending test was carried out on the samples to determine the effect of welding speed on the bending behaviour of the welded joints. In conclusion, we observed no visible welding defect in the weld seams at the three feed rates upon the bending test. No macro-welding defects such as porosity, macro-crack, burning groove on the surfaces of the weld seams were found either, which in turn led to the undamaged deformation in the samples during the bending test. It was found that the formation of the macro- and micro-porosities in the root section of the weld seam did not negatively affect the bending behaviour of the samples. However, the heat generated during the welding process caused the weld zone to soften. Likewise, we also determined that during the production, cold deformation caused the hardness of the base metal to decrease [20]. This thus made the weld zone more ductile as well as prevented cracks from the bending. Therefore, the welded samples joined at three welding speeds will be used safely by bending these samples at any angle up to $180^{\circ}$ depending on the service conditions after the welding process.

\section{Conclusions}

AA5754 Al alloy sheets were joined using different welding speeds by MIG welding method and their macrostructure, microstructure, and mechanical properties were examined. The results are summarized below:

1. AA5754 Al alloy sheets were joined using the MIG welding method at different welding speeds.

2. It was determined that the welding speed affected the weld seam, penetration, and microstructural properties of the welded joints. The increase in the welding speed affected the heat input, which in turn decreased the penetration of the weld seam. Macro- and micro-porosities were observed in the sections close to the root sections of the weld seams.

3. An increase in welding speed led the weld metal to have finer micro-particles.

4. The increase in hardness of the weld centre was associated with the increase in the welding speed. The hardness of the weld metal of all samples was higher than both HAZ and base metal.

5 . It was observed that the tensile strength of the samples welded by MIG method decreased at the rate of 3-59\% compared to the base metal. This decrease was associated with the increase in the welding speed and led to the formation of welding defects such as porosity in the weld seam and insufficient penetration.

6 . During the bending test, the welded samples began to deform at $180^{\circ}$.

\section{References}

[1] Tawfik, B. E., Leheta, H., Elhewy, A., Elsayed, T.: International Journal of Naval Architecture and Ocean Engineering, 9, 2017, p. 185. doi:10.1016/j.ijnaoe.2016.09.005

[2] Ertuğ, B., Kumruoğlu, L. C.: American Journal of Engineering Research, 4, 2015, p. 146.

[3] Sakiyama, T., Murayama, G., Naito, Y., Saita, K., Miyazaki, Y., Oikawa, H., Nose, T.: Nippon Steel Technical Report, 103, 2013, p. 91.

[4] Solazzi, L.: FME Transactions, 40, 2012, p. 57. 
[5] Lin, Y. K., Wang, S. H., Chen, R. Y., Hsieh, T. S., Tsai, L., Chiang, C. C.: Materials, 10, 2017, p. 275. doi:10.3390/ma10030275

[6] Sanders Jr., R. E., Hollinshead, P., Simielli, E. A.: Materials Forum, 28, 2004, p. 53.

[7] Liu, J., Tan, M. J., Jarfors, A. E. W., Aue-u-lan, Y., Castagne, S.: Materials and Design, 31, 2010, p. 66. doi:10.1016/j.matdes.2009.10.052

[8] Erdoğan, M.: Structure and Properties of Engineering Alloys: Nonferrous Metals. Ankara, Nobel Yayin 2001.

[9] Çam, G., Mistıkoğlu, S.: Journal of Materials Engineering and Performance, 23, 2014, p. 1936. doi:10.1007/s11665-014-0968-x

[10] Çevik, B., Özçatalbaş, Y., Gülenç, B.: Practical Metallography, 53, 2016, p. 6. doi:10.3139/147.110363

[11] Çevik, B., Özçatalbaş, Y., Gülenç, B.: Kovove Mater., 54, 2016, p. 241. doi:10.4149/km_2016_4_241

[12] Odabaş, C.: Aluminum Welding. Istanbul, Askaynak 2007.

[13] Durgutlu, A.: Journal of Polytechnic, 10, 2007, p. 271. (In Turkish) doi:10.2339/2007.10.3.271-276

[14] Yeni, Ç., Sayer, S., Pakdil, M.: Kovove Mater., 47, 2009, p. 341.

[15] Rapp, J., Glumann, C., Dausinger, F., Hugel, H.: Optical and Quantum Electronics, 27, 1995, p. 1203. doi:10.1007/BF00326476
[16] Taban, E., Kaluc, E.: Kovove Mater., 44, 2006, p. 25.

[17] Çevik, B.: Materials Research Express, 5, 2018, p. 066540. doi:10.1088/2053-1591/aacbbc

[18] Çevik, B., Gülenç, B.: Materials Research Express, 5, 2018, p. 086520. doi:10.1088/2053-1591/aad3b0

[19] Eryürek, İ. B.: Gas Metal Arc (MIG/MAG) Welding. Istanbul, Askaynak 1998.

[20] Ateş, H., Özdemir, A. T., Uzun, M., Uygur, I.: Scientia Iranica B, 24, 2017, p. 1950. doi:10.24200/sci.2017.4285

[21] Dudzik, K.: Journal of KONES Powertrain and Transport, 18, 2011, p. 73.

[22] Cueca, F., Patarroyo, A., Rojas, F., Solano, E., Morales, A., Muñoz, R.: Ship Science \& Technology, 6, 2012, p. 43.

[23] Casalino, G., Mortello, M., Leo, P., Benyounis, K. Y., Olabi, A. G.: Materials and Design, 61, 2014, p. 191. doi:10.1016/i.matdes.2014.04.060

[24] Liu, A., Tang, X., Lu, F.: Materials and Design, 50, 2013, p. 149. doi:10.1016/j.matdes.2013.02.087

[25] Dilthey, U., Brandenburg, A., Reich, F.: Welding in the World, 50, 2006, p. 7. doi:10.1007/BF03266530

[26] El-Batahgy, A., Kutsuna, M.: Advances in Materials Science and Engineering, 2009, 2009, Article ID 974182. doi: $10.1155 / 2009 / 974182$ 